MaPan : Jurnal Matematika dan Pembelajaran

p-ISSN: 2354-6883 ; e-ISSN: 2581-172X

Volume 7 No 1, June 2019 (1-15)

DOI: https://doi.org/10.24252/mapan.2019v7n1a1

\title{
INTEGRASI ETNOMATEMATIKA DENGAN MODEL PEMBELAJARAN PROBING-PROMPTING UNTUK MELATIH KOMUNIKASI MATEMATIS SISWA
}

\author{
Agus Prasetyo Kurniawan1), Ahmad Choirul Anam²), Abdussakir ${ }^{3)}$, Imam Rofiki ${ }^{4)}$ \\ 1,2Universitas Islam Negeri Sunan Ampel Surabaya \\ 3,4Universitas Islam Negeri Maulana Malik Ibrahim Malang \\ 1,2J1. Ahmad Yani No. 17 Surabaya, 3,4J1. Gajayana No. 50 Malang \\ E-mail: agustyo@sunan-ampel.ac.id ${ }^{11}$, ahmadchoirul1994@gmail.com²), \\ sakir@mat.uin-malang.ac.id ${ }^{3}$, imam.rofiki@uin-malang.ac.id ${ }^{4}$
}

Submitted: 23-04-2019, Revised: 26-06-2019, Accepted: 27-06-2019

\begin{abstract}
Abstrak:
Etnomatematika menjadi kajian tren penelitian saat ini. Etnomatematika memberikan pengaruh positif dalam pembelajaran matematika dengan melibatkan potensi budaya. Matematika perlu dikomunikasikan dengan menyisipkan budaya sehingga siswa mudah memahami materi. Oleh karena itu, etnomatematika perlu diintegrasikan dengan suatu model pembelajaran. Dengan demikian, tujuan penelitian ini adalah untuk mengembangkan perangkat pembelajaran model probing-prompting berbasis etnomatematika yang dapat melatih komunikasi matematis siswa. Penelitian ini menggunakan model pengembangan Instructional Development Institute (IDI) dengan tiga tahapan, yaitu menentukan, mengembangkan, dan mengevaluasi. Subjek penelitian adalah 30 siswa kelas 8 MTs Negeri Sidorejo Banyuwangi. Pengumpulan data dilakukan melalui angket, observasi, lembar validasi, dan tes. Perangkat pembelajaran yang dikembangkan berupa kisi-kisi soal, soal tes, LKS, dan RPP. Hasil penelitian menunjukkan bahwa perangkat pembelajaran memenuhi kriteria valid, praktis, dan efektif. Perangkat pembelajaran ini dapat digunakan guru untuk mengembangkan kemampuan komunikasi matematis siswa.
\end{abstract}

Kata Kunci: Etnomatematika, Komunikasi Matematis, Probing-Prompting

\section{INTEGRATION OF ETHNOMATHEMATICS WITH PROBING- PROMPTING LEARNING MODEL TO TRAIN STUDENTS' MATHEMATICAL COMMUNICATION}

\begin{abstract}
:
Ethnomatematics becomes trending study currently. It gives positive influence in learning mathematics by involving cultural potential. Mathematics needs to be communicated by integrating culture so that students easily understand the material. Therefore, ethnomatematics needs to be integrated with a learning model. Thus, the purpose of this study is to develop an ethnomatematics-based probing-prompting learning device that can train student's mathematical communication. The study used a development model of the Instructional Development Institute (IDI) with three stages, namely defining, developing, and evaluating.
\end{abstract}

Copyright ( $\odot$ 2019, MaPan : Jurnal Matematika dan Pembelajaran 
The research subjects were 30 eighth grade students at MTs Negeri Sidorejo Banyuwangi. Data were collected through questionnaire, observation, validation sheet, and test. The learning device consists of the prediction of test problems, test problems, student's worksheet, and lesson plan. The result of the study shows that the learning device fulfill valid, practical, and effective criterion. The learning device can be used by teachers to develop students' mathematical communication ability.

Keywords: Etnomathematics, Mathematical Communication, Probing-Prompting

How to cite: Kurniawan, A. P., Anam, A. C., Abdussakir, \& Rofiki, I. (2019). Integrasi etnomatematika dengan model pembelajaran probing-prompting untuk melatih komunikasi matematis siswa. MaPan : Jurnal Matematika dan Pembelajaran, 7(1), 1-15.

\section{PENDAHULUAN}

Komunikasi matematika merupakan aspek penting yang harus dikuasai siswa secara maksimal (Brendefur \& Frykholm, 2000; Cai, Jakabcsin, \& Lane, 1996; Cooke \& Buchholz, 2005; NCTM, 2000). Namun, fakta di sekolah menunjukkan bahwa banyak siswa belum menguasai kemampuan komunikasi matematika dengan baik. Siswa mengalami hambatan dalam mengomunikasikan ide-idenya untuk menyelesaikan masalah matematika. Penyebabnya adalah siswa kesulitan memahami objek matematika yang sifatnya abstrak, sehingga kemampuan komunikasi matematika siswa cenderung rendah.

Kesulitan tersebut dapat teratasi jika siswa mampu mengomunikasikan persoalan matematika dan mencari solusinya dengan model matematika yang benar. Hal ini juga menjadi permasalahan bagi guru ketika siswa diberikan soal cerita, siswa susah memahami soal dan mengerjakannya karena siswa belum terbiasa menggunakan suatu model dan menggunakan strategi yang tepat. Padahal, persoalan matematika bisa lebih mudah dipahami jika dikerjakan dengan memodelkan suatu permasalahan dalam bentuk gambar, diagram, atau tabel. Uraian tersebut menunjukkan bahwa kemampuan komunikasi matematika adalah faktor pendukung yang dapat meningkatkan pemahaman matematika siswa.

Komunikasi matematika menjadi bagian penting dalam pengembangan pemahaman matematika siswa (NCTM, 2000). Hasil penelitian terdahulu menunjukkan bahwa komunikasi matematika dapat mengembangkan pemahaman matematis siswa (Albert, 2000; Martin, 2015; Pugalee, 2001, 2004; Santos \& Semana, 2015; Shield \& Galbraith, 1998; Sierpinska, 1998). Oleh karena itu, kemampuan komunikasi matematika seharusnya dikuasai siswa dalam 
proses pembelajaran matematika. Kemampuan komunikasi matematika siswa dapat dikembangkan melalui penyampaian ide secara tertulis dan lisan. Siswa dapat berlatih untuk bekerja sama, menyatakan, menggambarkan, mendengarkan, menjelaskan dan menanyakan melalui diskusi dengan siswa lain untuk mengasah kemampuan komunikasinya, sehingga siswa dapat dengan mudah memahami konsep matematika dengan membangun pengetahuan mereka sendiri dari pengetahuan sebelumnya dan dengan bimbingan guru.

Beberapa penelitian sebelumnya telah melaporkan rendahnya kemampuan komunikasi matematika siswa (Baxter, Woodward, \& Olson, 2005; Heyd-Metzuyanim, 2013; Kostos \& Shin, 2010). Oleh karena itu, perlu adanya pembenahan dalam proses pembelajaran matematika. Pembelajaran probingprompting memiliki paradigma konstruktivis dan memfokuskan pada aspek proses berpikir. Pembelajaran probing-prompting termasuk salah satu tipe model pembelajaran kooperatif dengan cara memberikan pertanyaan yang sifatnya menggali dan menuntun (membimbing) serta menumbuhkan proses berpikir siswa dengan mengaitkan pengetahuan awal dan pengalaman siswa dengan pengetahuan baru yang sedang dipelajari. Model pembelajaran probingprompting terbukti dapat mengembangkan aktivitas siswa dalam pembelajaran (Alfian, Dwijanto, \& Sunarmi, 2017; Mayasari, Irwan, \& Mirna, 2014).

Pembelajaran dengan pendekatan berpikir dan berbasis masalah bertujuan untuk menstimulasi siswa agar dapat mengonstruksi sendiri pengetahuannya. Siswa diharapkan dapat melakukan berbagai aktivitas belajar yang efektif tanpa dibantu oleh guru sehingga peran guru sebagai fasilitator bukan hanya sebagai pemberi informasi (Darkasyi, Johar, \& Ahmad, 2014), sehingga guru perlu menentukan model pembelajaran yang tepat. Salah satu model pembelajaran yang dapat dipilih adalah probing-prompting.

Pembelajaran model probing-prompting menjadi sarana yang dapat memberikan dukungan semangat kepada siswa dalam membangun pengetahuannya berdasarkan pengalaman sehari-hari siswa dan pengetahuan sebelumnya. Selain itu, pengalaman sehari-hari siswa terkait kearifan dan budaya lokal juga perlu dimaksimalkan. Seiring perkembangan zaman yang semakin canggih, tingkat kesadaran masyarakat terhadap budaya lokal perlu ditingkatkan, khususnya generasi muda (siswa). Modernisasi negatif menyebabkan menurunnya pemahaman siswa terhadap budaya lokal yang dapat berakibat pada lemahnya pemahaman matematika siswa. Rendahnya pemahaman matematika siswa terhadap objek matematika disebabkan 
kurangnya pemanfaatan benda-benda di sekitar siswa yang berkaitan dengan matematika. Oleh karena itu, diperlukan sebuah pembelajaran yang mengaitkan objek matematika dengan kehidupan nyata dan lingkungan budaya sehingga siswa mudah memahami matematika. Istilah ini dalam matematika dikenal dengan etnomatematika.

Etnomatematika adalah matematika yang diaplikasikan dalam budaya dan terdapat dalam kehidupan sehari-hari. Dalam mengaplikasikan etnomatematika membutuhkan suatu pendekatan pembelajaran konstruktivisme berbasis budaya untuk meningkatkan kemampuan komunikasi matematika. Etnomatematika digunakan untuk mengekspresikan hubungan antara budaya dan matematika (D'Ambrosio, 2001). Etnomatematika adalah matematika yang diaplikasikan oleh kelompok budaya tertentu atau kelompok masyarakat tertentu dalam memahami, mengomunikasikan, dan menggunakan konsep matematis (Barton, 1996; Gerdes, 1994).

Penelitian etnomatematika mencakup 4 aktivitas, yaitu aktivitas deskriptif, arkeologis, matematisasi, dan analitis (Barton, 1996). Aktivitas (tindakan/percakapan) manusia dan artefak dapat digunakan dalam pembelajaran matematika untuk mengungkap berpikir matematis (Palhares, 2012). Etnomatematika memberikan pengaruh positif dalam mengatasi kesulitan belajar siswa. Beberapa penelitian sebelumnya telah mengintegrasikan etnomatematika dalam pembelajaran matematika. Sharp (2015) mendeskripsikan hubungan antara kalender Hopi dan konsep pengukuran. Sousa \& Palhares (2016) mengembangkan tugas matematis dengan pelibatan konteks komunitas nelayan. Massarwe, Verner, Bshouty, \& Verner (2010) menyelidiki penggunaan ornamen dalam pembelajaran geometri. Fouze \& Amit (2018) mengembangkan keterampilan berpikir matematis melalui permainan cerita rakyat.

Etnomatematika menjadi tren saat ini karena menjadi salah satu alternatif unggulan dalam memfasilitasi individu di masyarakat dan siswa di sekolah. Dalam memahami matematika, pembelajaran berbasis etnomatematika dilakukan dengan cara mengaitkan antara budaya sekitar lingkungan siswa dengan materi matematika agar mudah memahaminya. Integrasi pendekatan pembelajaran etnomatematika di kelas matematika sekolah dianjurkan untuk mengatasi rendahnya prestasi belajar siswa (Unodiaku, 2013). Penggunaan pendekatan pembelajaran berbasis etnomatematika memberikan kesempatan pemahaman konsep dengan mengaitkan pengalaman siswa (Abiam, Abonyi, Ugama, \& Okafor, 2016). 
Pembelajaran probing-prompting berbasis etnomatematika yang valid, praktis, dan efektif merupakan tujuan penelitian ini yang diharapkan dapat melatih kemampuan komunikasi matematika siswa. Hasil penelitian ini dapat digunakan guru sebagai pedoman dalam merancang proses pembelajaran untuk mengembangkan kemampuan komunikasi matematis siswa.

\section{METODE PENELITIAN}

Penelitian pengembangan ini menggunakan model Instructional Development Institute (IDI) yang dikembangkan oleh University Consortium for Instructional Development and Technology (UCIDT, 1973) yang memuat 3 tahap aktivitas, yaitu menentukan, mengembangkan, dan mengevaluasi dengan rincian: (1) menentukan masalah pembelajaran, menganalisis konteks, dan mengorganisasi pengembangan (tahap penentuan); (2) menentukan tujuan pembelajaran, menentukan model/metode untuk pembelajaran, dan mengonstruksi prototipe (tahap pengembangan); dan (3) menguji prototipe, menganalisis hasil, serta merevisi dan mengimplementasikan (tahap evaluasi). Pada tahap akhir, produk pengembangan perlu direvisi. Kegiatan-kegiatan pada tahap sebelumnya dapat diulangi. Setelah perulangan beberapa kegiatan, produk pengembangan dapat diimplementasikan.Jika target pembelajaran belum tercapai, maka siklus kegiatan dalam model IDI perlu dilakukan. Alur kegiatan pengembangan model IDI disajikan pada gambar berikut.

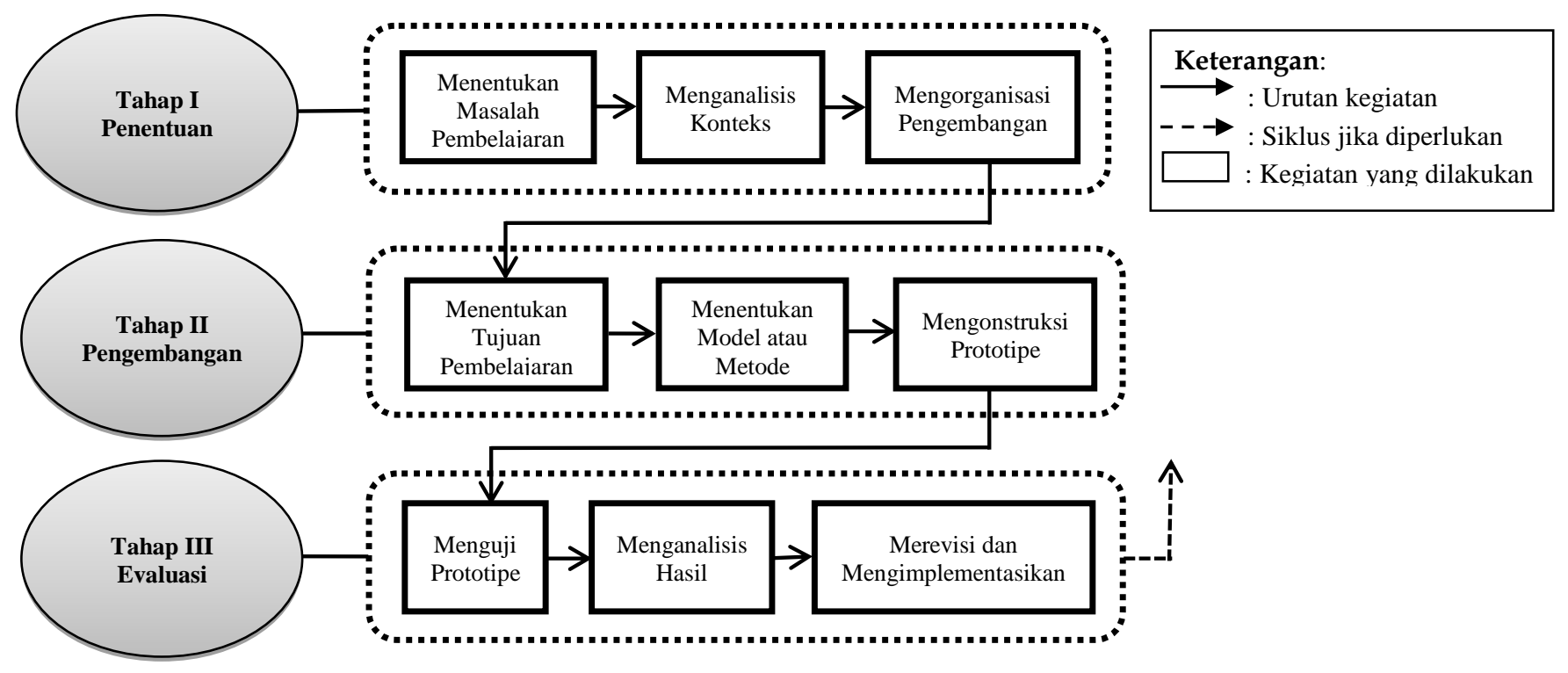

Gambar 1. Aktivitas-aktivitas Pengembangan dalam Model IDI 
Alasan pemilihan model IDI dibandingkan dengan model pengembangan lainnya karena IDI merupakan proses pengembangan desain pembelajaran yang lengkap dan komprehensif. Gustafson \& Branch (1997) menegaskan bahwa model IDI menyediakan alat komunikasi dan konseptual yang dapat digunakan untuk memvisualisasikan, memandu, dan mengelola proses urutan pembelajaran. Model IDI banyak digunakan para praktisi atau ilmuwan dalam proses pengembangan. Model IDI mendapat perhatian dan tempat utama dalam penelitian pengembangan.

Pada tahap penentuan, peneliti melakukan kegiatan analisis kebutuhan serta menentukan dan memformulasikan masalah pembelajaran; menganalisis kurikulum, karakteristik siswa, materi, dan proses pembelajaran di tempat penelitian; menyusun tugas, menyusun jadwal penelitian, mengatur tanggung jawab dan peran masing-masing orang yang terlibat dalam penelitian. Sementara pada tahap pengembangan, peneliti menentukan tujuan pembelajaran; menetapkan model pembelajaran probing-prompting berbasis etnomatematika; merancang dan mengembangkan perangkat pembelajaran yang berupa kisi-kisi soal tes, soal tes kemampuan komunikasi matematika, Lembar Kerja Siswa (LKS), dan Rencana Pelaksanaan Pembelajaran (RPP), serta instrumen-instrumen penelitian (lembar validasi perangkat pembelajaran, lembar pengamatan aktivitas siswa, lembar pengamatan keterlaksanaan sintaks pembelajaran, dan lembar angket respons siswa). Selanjutnya pada tahap evaluasi, peneliti mengajukan validasi perangkat pembelajaran dan instrumen penelitian kepada para ahli (validator); merevisi perangkat pembelajaran dan instrumen penelitian; melakukan uji coba terbatas perangkat pembelajaran; menganalisis hasil uji coba; merevisi dan mengimplementasikan perangkat pembelajaran.

Penelitian ini melibatkan 30 siswa kelas 8 MTs Negeri Sidorejo Banyuwangi. Pengumpulan data dilakukan dengan cara observasi, pemberian angket dan pemberian tes. Observasi (pengamatan) dilakukan untuk mengetahui aktivitas siswa dan keterlaksanaan sintaks pembelajaran. Sementara angket digunakan untuk mengetahui respons siswa selama proses pembelajaran. Sedangkan pemberian tes digunakan untuk mengetahui kemampuan komunikasi matematika siswa. Tes disusun dalam bentuk uraian yang terdiri atas 3 butir soal. Soal tes memuat unsur etnomatematika dan mengacu pada indikator kemampuan komunikasi matematika, yaitu: kemampuan mengekspresikan ide-ide matematis melalui lisan, tulisan, dan mendemonstrasikannya serta menggambarkannya secara visual; kemampuan 
menggunakan istilah, notasi matematika, dan strukturnya untuk menyajikan ide maupun menggambarkan hubungan model-model situasi; kemampuan memahami, menginterpretasikan, dan mengevaluasi ide-ide matematis baik secara lisan, tulisan, maupun dalam bentuk visual lain. Data yang diperoleh dalam penelitian dianalisis untuk mengetahui kevalidan, kepraktisan dan keefektifan perangkat pembelajaran yang dikembangkan.

\section{HASIL PENELITIAN DAN PEMBAHASAN}

Perangkat pembelajaran yang dikembangkan kemudian diterapkan pada kelas VIII di salah satu sekolah menengah di Banyuwangi. Hal ini bertujuan untuk menemukan kelemahan atau kekurangan terhadap perangkat pembelajaran sehingga mendapatkan sejumlah masukan untuk penyempurnaan perangkat pembelajaran yang sudah dikembangkan. Pada tahap awal, peneliti memperkenalkan pembelajaran matematika, yakni pembelajaran probing-prompting berbasis etnomatematika untuk melatih kemampuan komunikasi matematika. Selanjutnya, pelaksanaan pembelajaran dibantu dengan media pembelajaran eklipsjuno berbasis android. Media pembelajaran eklipsjuno ini memuat materi bangun ruang berbasis etnomatematika guna melatih kemampuan komunikasi matematis siswa dan diterapkan melalui telepon seluler. Dengan demikian, pembelajaran ini dapat dikategorikan sebagai mobile learning/m-learning (Motiwalla, 2007; Sarrab, 2012). Tampilan media pembelajaran eklipsjuno disajikan pada gambar berikut.
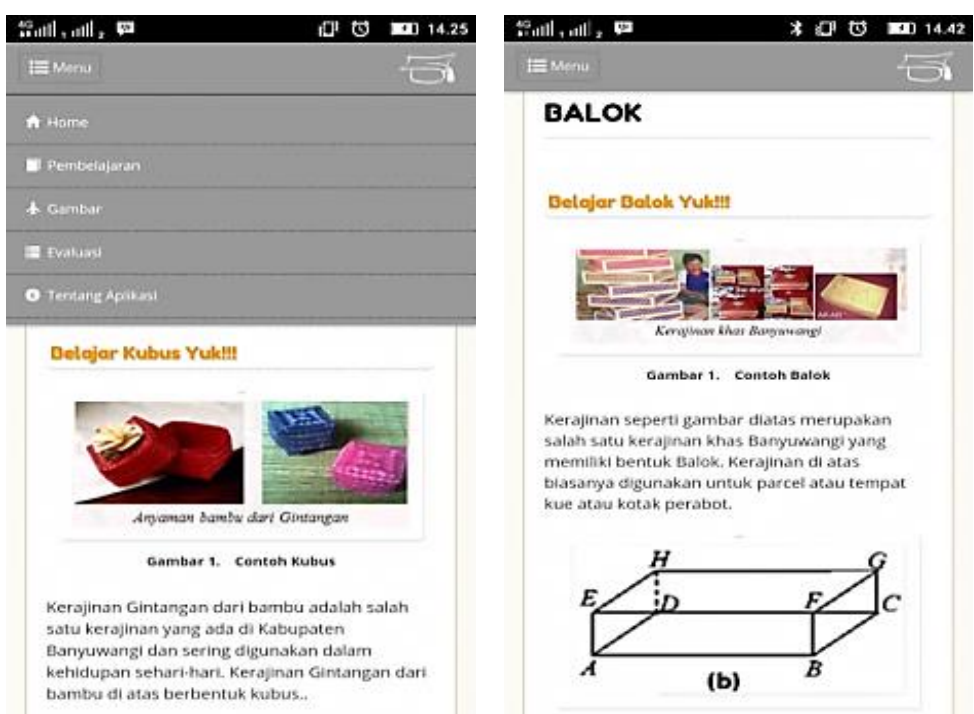

Gambar 2. Tampilan Media Pembelajaran Eklipsjuno 
Perangkat pembelajaran yang dikembangkan bernuansa etnomatematika yang menunjukkan budaya lokal Banyuwangi. Hal ini membuat siswa merasa senang dalam proses pembelajaran. Meskipun demikian, siswa masih membutuhkan bimbingan untuk memahami materi karena kegiatan belajar mengajar yang diterapkan menggunakan perangkat pembelajaran yang baru bagi siswa.

Selanjutnya, perangkat pembelajaran yang sudah dikembangkan divalidasi oleh tiga validator. Para validator tersebut adalah Validator 1 (ahli materi), validator 2 (ahli pembelajaran), dan validator 3 (praktisi pendidikan). Hasil uji kevalidan disajikan pada tabel berikut.

Tabel 1. Hasil Uji Kevalidan Perangkat Pembelajaran

\begin{tabular}{ccccccc}
\hline No & Kevalidan & V.1 & V.2 & V.3 & $\overline{\boldsymbol{X}}$ & Kepraktisan \\
\hline 1 & RPP & 3,70 & 3,90 & 4,10 & 3,94 & B \\
\hline 2 & LKS & 3,70 & 3,88 & 4,47 & 4,02 & B \\
\hline 3 & Kisi-Kisi Soal & 3,73 & 4,00 & 4,40 & 4,04 & B \\
\hline 4 & Soal Tes & 3,76 & 3,95 & 4,65 & 4,12 & B \\
\hline
\end{tabular}

Keterangan : V.1 : Validator 1

V.2 : Validator 2

$\mathrm{V} .2$ : Validator 3

$\bar{X} \quad$ : Rata - rata

Data pada tabel 1 menunjukkan bahwa RPP yang dikembangkan dikatakan valid, LKS dikatakan sangat valid, Kisi-kisi soal dikatakan sangat valid, dan soal tes juga dikatakan sangat valid. Sedangkan kepraktisan perangkat pembelajaran yang dikembangkan mendapatkan nilai B. Dengan demikian, perangkat pembelajaran yang dikembangkan dikatakan praktis dengan keterangan dapat digunakan dengan sedikit revisi.

Keefektifan perangkat pembelajaran dapat dilihat dari 4 aspek, yaitu aktivitas siswa, keterlaksanaan sintaks pembelajaran, respons siswa, dan tes hasil belajar. Pengamatan aktivitas siswa dilakukan oleh dua orang pengamat dalam dua kali pertemuan proses pembelajaran, yang mana masing-masing pertemuan dilaksanakan selama $2 \times 40$ menit. Hasil pengamatan aktivitas siswa disajikan pada Tabel 2. Berdasarkan data Tabel 2, persentase aktivitas siswa aktif sebesar $97,1 \%$ dan siswa pasif sebesar 2,9\%. Dua aktivitas yang banyak dilakukan siswa adalah 1) mendengarkan atau memperhatikan penjelasan guru dengan persentase 30,7\% dan 2) bertanya, berdiskusi, mengomunikasikan ide/gagasan matematis, atau menyampaikan pendapat kepada teman/guru 
dengan persentase $24,4 \%$. Hal ini menunjukkan bahwa siswa terlibat aktif dalam mengomunikasikan ide matematis.

Tabel 2. Hasil Pengamatan Aktivitas Siswa

\begin{tabular}{clc}
\hline No & \multicolumn{1}{c}{ Aktivitas Siswa } & Persentase \\
\hline 1 & Mendengarkan atau memperhatikan penjelasan guru & $30,7 \%$ \\
\hline 2 & $\begin{array}{l}\text { Membaca atau memahami masalah di media pembelajaran } \\
\text { eklipsjuno, LKS, atau buku }\end{array}$ & $8,8 \%$ \\
\hline 3 & $\begin{array}{l}\text { Menyelesaikan masalah atau menemukan cara dan } \\
\text { jawaban dari masalah }\end{array}$ & $13,5 \%$ \\
\hline 4 & $\begin{array}{l}\text { Menulis materi yang diajarkan, menghargai pendapat } \\
\text { teman, melakukan presentasi, atau mengerjakan soal }\end{array}$ & $4,5 \%$ \\
\hline 5 & $\begin{array}{l}\text { Bertanya, berdiskusi, mengomunikasikan ide/gagasan, } \\
\text { atau menyampaikan pendapat kepada teman/guru }\end{array}$ & $24,4 \%$ \\
\hline 6 & Menarik simpulan suatu prosedur/konsep & $15,2 \%$ \\
\hline 7 & $\begin{array}{l}\text { Perilaku yang tidak relevan dengan kegiatan belajar } \\
\text { mengajar }\end{array}$ & $2,9 \%$ \\
\hline & \multicolumn{1}{c}{ Jumlah } \\
\hline
\end{tabular}

Keterangan : Aktivitas No 1 sampai 6 termasuk kategori aktif Aktivitas No 7 termasuk kategori pasif

Keefektifan perangkat pembelajaran juga dilihat dari keterlaksanaan sintaks pembelajaran. Terdapat 24 langkah pembelajaran yang harus dilaksanakan selama proses pembelajaran pada dua kali pertemuan. Akan tetapi, dalam pelaksanaannya tidak semua langkah dapat dilaksanakan. Pada pertemuan I hanya terlaksana 23 langkah pembelajaran yang mendapatkan persentase sebesar 96\%, dan terlaksana 22 langkah pada pertemuan II dengan persentase sebesar $92 \%$.

Respons siswa merupakan kegiatan selanjutnya yang digunakan untuk menilai keefektifan perangkat pembelajaran yang dikembangkan. Respons siswa yang dinilai adalah respons terhadap pelaksanaan pembelajaran, LKS, dan media pembelajaran. Hasil angket respons siswa secara keseluruhan dapat dilihat pada tabel berikut.

Tabel 3. Hasil Angket Respons Siswa

\begin{tabular}{clc}
\hline No. & \multicolumn{1}{c}{ Respons Siswa } & Persentase Skor \\
\hline 1 & Pelaksanaan Pembelajaran & $89.04 \%$ \\
\hline 2 & LKS & $85.16 \%$ \\
\hline 3 & Media Pembelajaran & $86.67 \%$ \\
\hline \multicolumn{2}{c}{ Rata-rata } \\
\hline \multicolumn{2}{c}{$\mathbf{8 6 . 9 5 \%}$} \\
\hline
\end{tabular}


Berikut ini disajikan tampilan LKS yang dapat dilihat pada gambar berikut. LKS yang dikembangkan memuat pembelajaran probing-prompting berbasis etnomatematika dengan melibatkan budaya Banyuwangi. Dalam pengonstruksian LKS, peneliti juga melibatkan aspek komunikasi matematis.
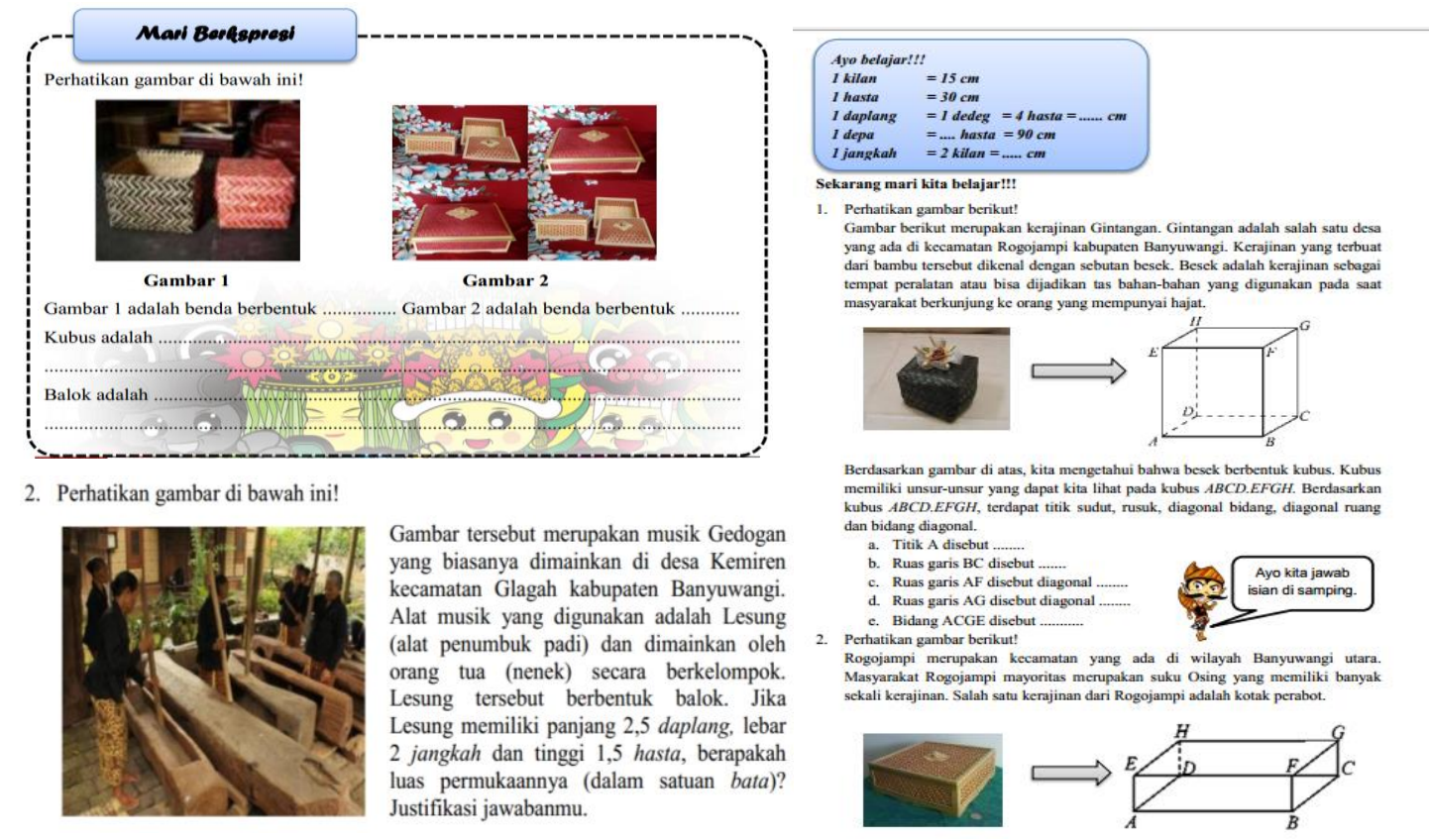

Gambar 3. Tampilan Lembar Kerja Siswa

Kegiatan terakhir dalam mengetahui keefektifan perangkat pembelajaran adalah tes hasil belajar. Dalam penelitian ini, dilaksanakan tiga kali tes yang dibagi ke dalam dua pertemuan. Tes pertama terkait kuis dalam lembar kerja siswa, tes kedua terkait latihan soal, dan tes ketiga terkait soal tes kemampuan komunikasi matematika. Penilaian terhadap tes hasil belajar dilihat dari ketuntasan minimal yang sudah ditetapkan, yaitu nilai skor siswa lebih dari 75. Hasil tes hasil belajar menunjukkan bahwa 30 siswa tuntas pada tes pertama, pada tes yang kedua terdapat 25 siswa yang tuntas dan 5 siswa belum tuntas, dan pada tes yang ketiga terdapat 23 siswa yang tuntas dan 7 siswa belum tuntas. Persentase secara keseluruhan menunjukkan bahwa $86,67 \%$ siswa tuntas dan 13,34\% siswa belum tuntas. Dengan demikian, keseluruhan siswa telah mencapai kompetensi yang telah ditentukan.

Salah satu contoh hasil pekerjaan siswa terkait soal tes yang dikembangkan pada soal Nomor 3 disajikan pada Gambar 4. Soal tersebut dibuat untuk mendorong munculnya kemampuan siswa dalam 
mengomunikasikan ide/gagasan matematis melalui pemahaman soal dan interpretasi jawaban. Hasil jawaban tersebut diperoleh menggunakan lembar tes. Lembar tes dilakukan dengan tujuan untuk mengetahui kemampuan komunikasi matematika siswa dalam memecahkan suatu permasalahan matematika.

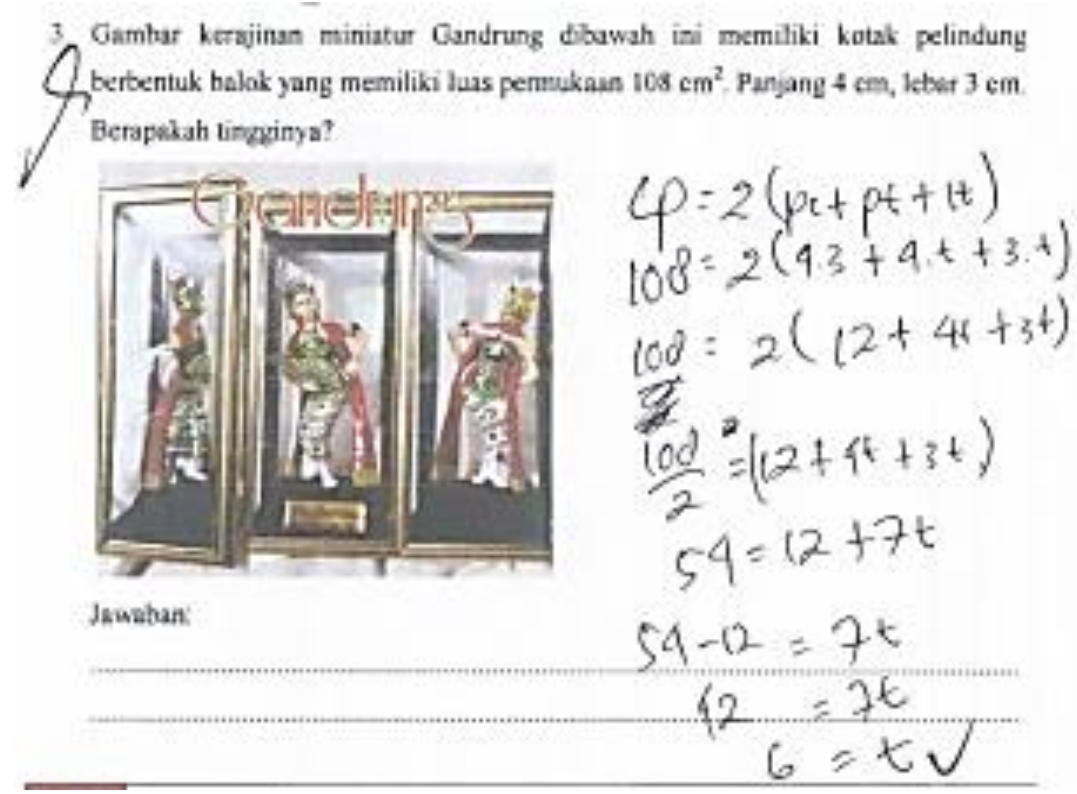

Gambar 4. Hasil Pekerjaan Siswa

Hasil penelitian ini menunjukkan bahwa penerapan model pembelajaran probing-prompting berbasis etnomatematika dapat memicu tingginya aktivitas siswa dalam proses pembelajaran. Hal ini sejalan dengan hasil penelitian Alfian, Dwijanto, \& Sunarmi (2017) yang menunjukkan bahwa model pembelajaran probing-prompting efektif dalam mengembangkan aktivitas berpikir kreatif dan memicu rasa ingin tahu siswa. Sementara hasil penelitian Mayasari, Irwan, \& Mirna (2014) menunjukkan bahwa pembelajaran model probing-prompting dapat memberikan pengaruh positif dalam meningkatkan aktivitas siswa. François \& Stathopoulou (2012) mengemukakan bahwa aktivitas matematika seperti menghitung, mengukur, dan menemukan akan lebih efektif jika menggunakan etnomatematika, karena siswa dapat mengeksplorasi pengalaman pribadinya ke dalam matematika secara formal. Etnomatematika membuat matematika sekolah menjadi bermakna dan relevan untuk mempromosikan kualitas pengalaman akademik siswa (Rosa \& Orey, 2011).

Hasil tes kemampuan komunikasi matematika menunjukkan bahwa terdapat $12(40,00 \%)$ siswa berkemampuan komunikasi matematika tinggi, 13 
$(43,34 \%)$ siswa berkemampuan komunikasi matematika sedang, dan 5 (16,67\%) siswa berkemampuan komunikasi matematika rendah. Hal ini menunjukkan bahwa mayoritas siswa memiliki kemampuan komunikasi matematika sedang dan tinggi. Temuan ini selaras dengan hasil penelitian Lomibao, Luna, \& Namoco (2016) yang melaporkan bahwa komunikasi matematika efektif dalam meningkatkan pencapaian prestasi belajar siswa. Sementara hasil penelitian Anintya, Pujiastuti, \& Mashuri (2017) menunjukkan bahwa komunikasi matematika dengan model resource based learning mencapai ketuntasan klasikal.

Temuan lain penelitian ini, yaitu siswa mampu memberikan argumentasi yang logis dalam proses mempertahankan kebenaran jawabannya. Siswa memberikan penjelasan dan alasan yang relevan dalam penyelesaian soal. Meskipun demikian, ada siswa yang memberikan argumentasi tanpa upaya pemahaman mendalam. Pemahaman siswa menjadi tidak bermakna. Temuan ini selaras dengan hasil penelitian yang menginvestigasi argumentasi individu dalam penyelesaian tugas matematis (Rofiki, Nusantara, Subanji, \& Chandra, 2017).

\section{SIMPULAN}

Penelitian etnomatematika menjadi alternatif solusi dalam pembelajaran matematika sehingga diharapkan dapat mengembangkan kemampuan matematika siswa, khususnya komunikasi matematis. Perangkat pembelajaran matematika model probing-prompting berbasis etnomatematika yang dikembangkan memenuhi kategori valid dengan nilai rata-rata total kevalidan RPP sebesar 3,94, LKS sebesar 4,02, kisi-kisi soal sebesar 4,04, dan soal tes sebesar 4,12. Selain itu, perangkat pembelajaran dikatakan praktis dengan penilaian B. Perangkat pembelajaran juga memenuhi kategori efektif dengan keterlaksanaan sintaks pembelajaran pada pertemuan I dan II masing-masing sebesar $96 \%$ dan 92\%, persentase aktivitas siswa sebesar 97,1\%, persentase respons positif siswa terhadap pembelajaran sebesar $97,1 \%$, dan persentase hasil belajar siswa yang tuntas sebesar $86,67 \%$. Penelitian ini memfokuskan pada etnomatematika yang berupa benda atau kerajinan lokal khas Banyuwangi seperti kerajinan Gintangan, Besek, Lesung (musik gedogan), miniatur Gandrung, dan sebagian menggunakan hitungan lokal (seperti kilan, jangkah, hasta, dan depa). Penelitian selanjutnya terkait perangkat pembelajaran dapat mempertimbangkan etnomatematika pada bidang lainnya, seperti adat istiadat, kebudayaan, candi, atau artefak. Hal ini bertujuan untuk mengenalkan budaya daerah kepada siswa sekaligus sebagai media dalam meningkatkan 
pemahaman matematika siswa. Penelitian integrasi etnomatematika dalam pembelajaran matematika sekolah perlu diintensifkan untuk mengembangkan keterampilan berpikir matematis siswa.

\section{DAFTAR PUSTAKA}

Abiam, P. O., Abonyi, O. S., Ugama, J. O., \& Okafor, G. (2016). Effects of ethnomathematics-based instructional approach on primary school pupils' achievement in geometry. Journal of Scientific Research and Reports, 9(2), 1-15.

Albert, L. R. (2000). Outside-in - inside-out: Seventh-grade students' mathematical thought processes. Educational Studies in Mathematics, 41(2), 109-141. https:// doi.org/10.1023/A:1003860225392

Alfian, M. H., Dwijanto, D., \& Sunarmi, S. (2017). Effectiveness of probingprompting learning models with scaffolding strategy to mathematics creative thinking ability and enthusiasm. Unnes Journal of Mathematics Education, 6(2), 249-257.

Anintya, Y. A., Pujiastuti, E., \& Mashuri, M. (2017). Analysis of mathematical communication skills viewed from student learning styles in eighth grader students in learning resource based learning model. Unnes Journal of Mathematics Education, 6(1), 37-43.

Barton, B. (1996). Making sense of ethnomathematics: Ethnomathematics is making sense. Educational Studies in Mathematics, 312(1), 201-233.

Baxter, J. A., Woodward, J., \& Olson, D. (2005). Writing in mathematics: An alternative form of communication for academically low-achieving students. Learning Disabilities Research and Practice, 20(2), 119-135. https:// doi.org/10.1111/j.1540-5826.2005.00127.x

Brendefur, J., \& Frykholm, J. (2000). Promoting mathematical communication in the classroom: Two preservice teachers' conceptions and practices. Journal of Mathematics Teacher Education, 3(2), 125-153. https:// doi.org/10.1023/A:1009947032694

Cai, J., Jakabcsin, M. S., \& Lane, S. (1996). Assessing students' mathematical communication. School Science and Mathematics, 96(5), 238-246. https:// doi.org/10.1111/j.1949-8594.1996.tb10235.x

Cooke, B. D., \& Buchholz, D. (2005). Mathematical communication in the classroom: A teacher makes a difference. Early Childhood Education Journal, 32(6), 365-369. https:// doi.org/10.1007/s10643-005-0007-5

D'Ambrosio, U. (2001). What is ethnomathematics, and how can it help children in schools? Teaching Children Mathematics, 7(6), 308-310.

Darkasyi, M., Johar, R., \& Ahmad, A. (2014). Peningkatan kemampuan komunikasi matematis dan motivasi siswa dengan pembelajaran pendekatan Quantum Learning pada siswa SMP Negeri 5 Lhokseumawe. Jurnal Didaktik Matematika, 1(1), 21-34. 
Fouze, A. Q., \& Amit, M. (2018). Development of mathematical thinking through integration of ethnomathematics folklore game in math instruction. Eurasia Journal of Mathematics, Science and Technology Education, 14(2), 617630. https:/ / doi.org/10.12973/ ejmste/80626

François, K., \& Stathopoulou, C. (2012). In-between critical mathematics education and ethnomathematics: A philosophical reflection and an empirical case of a Romany students' group mathematics education. Journal for Critical Education Policy, 10(1), 234-247.

Gerdes, P. (1994). Reflections on ethnomathematics. For the Learning of Mathematics, 14(2), 19-22. https:/ / doi.org/10.1145/3085228.3085284

Gustafson, K. L., \& Branch, R. M. (1997). Revisioning models of instructional development. Educational Technology Research and Development, 45(3), 7389. https:/ / doi.org/10.1007/BF02299731

Heyd-Metzuyanim, E. (2013). The co-construction of learning difficulties in mathematics-teacher-student interactions and their role in the development of a disabled mathematical identity. Educational Studies in Mathematics, 83(3), 341-368. https:// doi.org/10.1007/s10649-012-9457-z

Kostos, K., \& Shin, E. kyung. (2010). Using math journals to enhance second graders' communication of mathematical thinking. Early Childhood Education Journal, 38(3), 223-231. https://doi.org/10.1007/s10643-0100390-4

Lomibao, L. S., Luna, C. A., \& Namoco, R. A. (2016). The influence of mathematical communication on students' mathematics performance and anxiety. American Journal of Educational Research, 4(5), 378-382. https:// doi.org/10.12691/EDUCATION-4-5-3

Martin, C. L. (2015). Writing as a tool to demonstrate mathematical understanding. School Science and Mathematics, 115(6), 302-313. https:// doi.org/10.1111/ssm.12131

Massarwe, K., Verner, I., Bshouty, D., \& Verner, I. (2010). An ethnomathematics exercise in analyzing and constructing ornaments in a geometry class. Journal of Mathematics and Culture, 5(1), 1-20.

Mayasari, Y., Irwan, \& Mirna. (2014). Penerapan teknik probing-prompting dalam pembelajaran matematika siswa kelas VIII MTsN Lubuk Buaya Padang. Jurnal Pendidikan Matematika, 3(1), 56-61.

Motiwalla, L. F. (2007). Mobile learning: A framework and evaluation. Computers and Education, 49(3), 581-596. https:/ / doi.org/10.1016/j.compedu.2005.10.011

NCTM. (2000). Principles and standards for school mathematics. Reston, VA: National Council of Teachers of Mathematics.

Palhares, P. (2012). Mathematics education and ethnomathematics. A connection in need of reinforcement. REDIMAT-Journal of Research in Mathematics Education, 1(1), 79-92. 
Pugalee, D. K. (2001). Writing, mathematics, and metacognition: Looking for connections through students' work in mathematical problem solving. School Science and Mathematics, 101(5), 236-245. https:// doi.org/10.1111/j.1949-8594.2001.tb18026.x

Pugalee, D. K. (2004). A comparison of verbal and written descriptions of students' problem solving processes. Educational Studies in Mathematics, 55(1-3), 27-47. https:// doi.org/10.1023/B:EDUC.0000017666.11367.c7

Rofiki, I., Nusantara, T., Subanji, \& Chandra, T. D. (2017). Exploring local plausible reasoning: The case of inequality tasks. Journal of Physics: Conference Series, 943(1), 12002.

Rosa, M., \& Orey, D. (2011). Ethnomathematics: The cultural aspects of mathematics. Revista Latinoamericana de Etnomatemática: Perspectivas Socioculturales de La Educación Matemática, 4(2), 32-54.

Santos, L., \& Semana, S. (2015). Developing mathematics written communication through expository writing supported by assessment strategies. Educational Studies in Mathematics, 88(1), 65-87. https:/ / doi.org/10.1007/s10649-014-9557-z

Sarrab, M. (2012). Mobile learning (m-learning) and educational environments. International Journal of Distributed and Parallel Systems, 3(4), 31-38. https:// doi.org/10.5121/ijdps.2012.3404

Sharp, J. (2015). Relationships between the Hopi calendar and measurement concepts. Journal of Mathematics and Culture, 9(1), 30-51.

Shield, M., \& Galbraith, P. (1998). The analysis of student expository writing in mathematics. Educational Studies in Mathematics, 36(1), 29-52. https:// doi.org/10.1023/A:1003109819256

Sierpinska, A. (1998). Three epistemologies, three views of classroom communication: Constructivism, sociocultural approaches, interactionism. In H. Steinbring, M. G. B. Bussi, \& A. Sierpinska (Eds.), Language and communication in the mathematics classroom (pp. 30-62). Reston, VA: National Council of Teachers of Mathematics.

Sousa, J. F. P., \& Palhares, P. (2016). (Ethno) mathematical tasks in the context of proportional reasoning. Journal of Mathematics and Culture, 10(3), 101-110.

UCIDT. (1973). Instructional development institute model. Syracuse: The University Consortium for Instructional Development \& Technology.

Unodiaku, S. S. (2013). Effect of ethno-mathematics teaching materials on students' achievement in mathematics in Enugu State. Journal of Education and Practice, 4(23), 70-77. 